\title{
Ecological Community -- the Optimal Choice of Sustainable Urban Development
}

\author{
Zhou Yucui \\ Quzhou University, School of Economics and Trade Management, 324000
}

Keywords: urbanization; ecological community; sustainable urban development

\begin{abstract}
With the acceleration of the development of contemporary urbanization, the issue of urban differences and urban-rural differences is also attracting increasing attention. Seeking sustainable urban and rural development is an important strategic task of our country in the new historical stage. This paper puts forward that ecological community is the best choice of sustainable urban development, and expounds the basic tasks and main contents of ecological community construction.
\end{abstract}

\section{Introduction}

To accelerate the development of contemporary city, it brings prosperity to the society and also brings about many city problems, the western developed countries and some developing countries, inverse city urbanization expansion and malformation causing irreparable damage to the society and economy, scholars are working on research to solve the city problem fundamentally, the scholars in our country study on the influence of city, is also active in the social and economic development of the city power system, the author tries to explore a road for the city China characteristics, these studies will seek the theoretical foundation of Chinese city sustainable development of society, economy and environment[1].

\section{Disadvantages of Traditional Urbanization Road}

The traditional urbanization road takes the city as the center and ignores the vast countryside. The development of various types of regional planning, city planning, urban and rural planning in city is the core of the development of social economic development goals, rarely take into account the development of rural regional social economy, that since the reform and opening up, China's economy has made great development in the city at the same time, the countryside is relatively backward. In addition to the rapid development of rural areas in some areas, a considerable part of the rural areas still have the advantage of small peasant economy. The development of rural industry is slow, and the development of urban and rural areas is out of line. In addition to a few urban and rural integration areas such as the Yangtze River Delta and the Pearl River Delta, the two element structure of urban and rural areas in China still exists. There are some trends of strengthening in some areas. The difference between urban and rural areas has not been narrowed, but on the contrary, it has expanded to varying degrees. From the view of system theory, city and countryside are two interdependent subsystems in the whole social economy system, to make the whole function of the system reach the optimal state, we must make each subsystem of mutual coordination and promotion to urban-rural interaction, it is not conducive to the development of the social economy of the whole region. Is not conducive to the further development of the city.

Since the founding of new China after decades of practice, the traditional mode of destruction of city ecological environment gradually revealed, although in recent years the city construction pay attention to ecological and environmental problems, but to deal with the relationship between human and ecological environment problems in practice is still no fundamental breakthrough, the concept of human dominated environment still dominates the decision-making behavior people, urban and rural ecological environment deterioration. According to the latest bulletin China environment shows that the environmental problem in China is still very serious, river and lake water quality grade $\mathrm{V}$ and worse than grade $\mathrm{V}$ proportion is $50 \%$, acid rain area, East China, 
Southern China, central and southwestern areas of acid rain pollution is most serious, the industrial and agricultural production, buildings, ecological environment and even human health harm. The smoke and dust pollution, the inhalable particles accounted for a large proportion, seriously endanger people's health, according to the WHO in 201620 city database, the world's highest concentration of PM2.5, China 4 city on the list, in Hebei Province, a serious impact on the ecological environmental quality of the capital circle.

At the present stage city most area of our country road is imitation, rarely consider the integration with the local ecological environment, not to mention the establishment of the society, according to the principle of ecology, economic natural complex system, resulting in structural convergence, poor stability, lower self adjustment ability of competition, is not conducive to sustainable development. For example, in real estate development, office buildings and residential areas are distributed according to grade, and high grade office buildings and housing are overdeveloped. In the industrial structure and the blind pursuit of high value-added, high profit industries, the real economy has not been given due attention, leading to the city and the surrounding rural economic development from many places, the convergence of industrial structure, resource utilization rate is reduced, the original mutual condition, mutual cooperation of the city into a rival. For example, in the aspect of urban construction, many cities are pursuing the center of town, there is a citizen square, there is a landmark building beside the square. In other areas, it is monotonous concrete structure (Concrete Block) because it has not been valued. In the area of urban greening, the single nature is even justified by the "expansion of vision". Based on the construction of the city is not from the overall regional planning concept, causing the city green space system planning and regional environmental planning coordination, many city failed to fully outside the city greenbelt ienna [3].

With the development of science and technology and urbanization, the pace of life accelerates and competition intensifies. People are under unprecedented pressure from life and work pressure, especially urban residents. The progress of science and technology is a double-edged sword, in the promotion of social progress and to facilitate the production and life of people at the same time, inevitably pull away people and people, between human and nature, human's economic value while greatly play, and a lot of power as natural persons had been brutally deprived. As a kind of emotional animal instinct desire of communication can not be achieved, the human taste of face-to-face communication is less and less, stopping, parties, visiting friends and relatives, the content of life to go shopping and tourism exchange of feelings is telephone contact, online chat, online shopping, online travel replaced. Parents and children cannot be reunited. Couples can't get together for a long time, lack of family ties and lack of friendship. The traditional honest interpersonal relationship is gradually disintegrating and replaced by utilitarianism and rational colors, resulting in belief crisis and emotional loneliness. The incidence of mental disorders, mental illness, divorce, drug abuse and crime has risen in many cities, which seriously threatens the stability of the society. The disadvantages of these traditional urbanization roads are not only sweeping the whole western country, but also spreading in cities all over China [2].

\section{The Basic Idea of Creating an Ecological Community}

Community is the carrier of people's social life in a certain area. It is a specific social, economic community and the basic area of people's life. The ecological community is a complex of society, economy and nature. The social, economic and natural complexes in different regions are different ecological communities. The global ecosystem community is the global natural and humanistic system. The natural humanities system at all levels under the largest mother system consists of different levels of ecosystem community system based on the strength and way of interrelation, and each ecosystem community is interrelated and restricted each other. The characteristics of the ecological community constitute the overall image of the community, which is mainly composed of the material civilization of the community, the spiritual civilization of the community, the community environment and the community structure. The community image is a concentrated embodiment of the difference between the communities. There are differences between urban 
communities and rural communities. There are differences between pure communities and mixed communities. There are differences between historical and cultural communities and modern civilized communities. The concept of ecological community system optimization is to follow the laws of nature, social and economic law in accordance with the ecological communities of various types in the system in place, from the system perspective, cooperation between coordination to correctly handle the relationship between economic, social and environmental and ecological communities, the combination of hybrid organic whole urban and rural development and gradually evolved into the interaction between urban and rural areas.

Is to use the idea of sustainable development to guide urban and rural future development and deal with the relationship between urban and rural areas to create ecological communities, but whether it is the city country, the traditional predatory development, full operation, self centred model of development must be completely abandoned. To restore growth, change the growth quality, meet the basic human needs, to ensure that the appropriate size of the population, protect and strengthen the resource base, improve technology and control its harm, decision-making coordination relation between environment and economy, is a strategic task for sustainable development, the ecological community construction must be as the guiding ideology. In the process of building the ecological economic relationship between human society and natural environment, the coordination between the four subsystems of population, resources, environment and development plays a key role. The fairness among the development subjects is also strongly advocated by the ecological community. One is the vertical fairness performance between the contemporary and future planning of urban and rural development in space to control and guide, arrange the temporal development and sufficient space for future development. On the other hand, it is horizontal equity. It shows that the development of a main body should not impair the health of other subjects, and correctly consider the overall coordination relationship between each development unit and its location and other units in planning. The sustainability of development is also the goal pursued by the construction of ecological communities. Negative zero growth can not fundamentally solve the future development of human society, which requires intensive development mode for urban and rural development and solving problems in development.

Humanism is increasingly becoming the basic value concept of urban and regional development. Its basic idea is to take people as the core. Adhering to the needs of humanization is the fundamental motivation and final destination of social and economic development. The specific requirements in the construction of ecological communities everywhere has taken pains to create a suitable living environment, optimize regional, urban spatial morphology, living facilities complete, convenient for people's diversity and individual needs. Pay attention to the ecological community to find a balance between economic, social, ecological, maximize the humanistic concern, which includes China classical philosophy of world unity of thought.

\section{Tasks and Contents of Ecological Community Construction}

The basic task of the construction of ecological community is: according to the principle of ecology, guided by the idea of sustainable development, with full respect for the human rights, effective development and utilization of various resources, protect the ecological environment, rational distribution of productive forces and all kinds of urban and rural community system, the interaction between urban and rural cooperation and coordination to achieve the economic benefit and social benefit and environmental benefit human life, to create efficient regional civilization.

The main contents of ecological community construction are as follows: 1, according to the principles of ecology, we plan the land use to coordinate the proportion of urban construction land, rural construction land, regional infrastructure land, ecological land and agricultural production land and so on. In this respect, the development of Curitiba's traffic axis and the model of mixed land use and development should be used for reference. 2, we should popularize clean production and clean energy, adjust product structure, improve technology, improve production equipment, recycle in the field, strengthen the whole process management of plants and production, and use pollution-free energy, and control pollution to a minimum. 3, to create a comprehensive ecological community. 
The traditional strict urban function zoning not only brings inconvenience to people's daily work and life, but also increases the commuter costs of residents, exacerbates the problem of urban traffic congestion, and on the other hand, improves the living environment of industrial and old urban areas. The construction of ecological community is to create a comprehensive community space which integrates living, work and life. overall planning of urban and rural transportation, energy, water conservancy, drainage, telecommunications, communications and other infrastructure, to become a strong support for the interactive cooperation between urban and rural areas, and to optimize urban and rural spatial structure plays a promoting and guiding role, also can make the infrastructure play a greater effect than the traditional city and countryside [4].

Centralized development along the traffic corridor. The axis of traffic radiated from the center of the city has become a corridor for high density land development, and the corridor between the corridors is an ecological land and a land for agricultural production. In this way, the high density area of the city is not a centralization, but a strip extension, which can greatly improve the ecological environment quality of the high density built-up area. integrated road traffic system. In the ecological community in city community and rural community road system to achieve the integration of any city roads in the shortest distance from the city, a rural settlements have the shortest distance path into the city, so high accessibility for the integration of urban and rural development to provide protection. improve the ecological consciousness of all the residents, and advocate a simple and frugal way of life with ecological civilization. In the whole population, we should carry out the protection of ecological environment education, enhance people's environmental awareness and environmental protection ability, so that people can consciously protect the ecological environment in daily life, such as saving resources, recycling, garbage sorting, replacing cars with steps. bus priority community traffic planning. The construction of ecological community should provide convenient and fast transportation services for most of the people, and fully reflect the fairness and impartiality of human ideals, which is also the goal pursued by efficient transportation. With the convenience of public transport system, private cars have no need for existence. Pollution problems, traffic congestion and energy shortages are all alleviated. community driven development model. The whole process of planning, design, construction, management and maintenance of the community is involved in the whole process of community residents, and the residents really become the owners of the community [5].

\section{References}

[1] Dow J. Uncertainty Aversion, Risk Aversion, and the Optimal Choice of Portfolio[J]. Econometrica, 1992, 60(1):197-204.

[2] Thomas P A, Mukassabi T A. Biological Flora of the British Isles: Ruscus aculeatus[J]. Journal of Ecology, 2014, 102(4):1083-1100.

[3] Yuan Y, Takahashi Y, Yabe M. Preferences for the Attributes of Household Kitchen Waste Source Separation Sertvices in China Using Latent Class Approach[J]. Journal- Faculty of Agriculture Kyushu University, 2015, 60(2):511-518.

[4] Toshimitsu T. The optimal choice of internal decision-making structures in a network industry[J]. Discussion Paper, 2017.

[5] Al-Qalawi U, Jemel H A, Alwaked A A. The Optimal Choice of Exchange-Rate Regime for Jordanian Dinar[J]. Journal of Economic Cooperation \& Development, 2017, 38(2). 